\title{
Quaternary ammonium-induced multidrug tolerant Streptococcus mutans persisters elevate cariogenic virulence in vitro
}

\author{
Ya-Ling Jiang ${ }^{1, \star}$, Wei Qiu ${ }^{1, \star}$, Xue-Dong Zhou ${ }^{1}$, Hao $\mathrm{Li}^{1}$, Jun-Zhuo Lu${ }^{1}$, Hockin HK Xu ${ }^{2}$, Xian Peng ${ }^{1}$, \\ Ming-Yun Li ${ }^{1}$, Ming-Ye Feng ${ }^{1}$, Lei Cheng ${ }^{1}$ and Biao Ren ${ }^{1}$
}

Dental caries are the most prevalent chronic infections in the oral cavity, and Streptococcus mutans acts as the main cariogenic bacterial species. Antibacterial quaternary ammonium compounds (QAs) have been developed to preveFnt or treat dental caries. However, there is no report on the tolerance of $S$. mutans to QAs. In this study, we investigated the development of $S$. mutans persistence induced by a novel dental caries defensive agent, dimethylaminododecyl methacrylate (DMADDM), for the first time. Typical biphasic killing kinetics for persisters were observed in both $\boldsymbol{S}$. mutans planktonic and biofilm cultures challenged by DMADDM at concentrations of 20 and $200 \mu \mathrm{g} \cdot \mathrm{mL}^{-1}$, respectively. The persisters tolerated six other antibiotics with different antibacterial mechanisms, while only daptomycin and vancomycin could slightly reduce the persister numbers in planktonic cultures. The distribution of persisters in DMADDM-treated biofilms was similar to that in the untreated control, except that the total biomass and biofilm height were significantly reduced. A higher exopolysaccharides (EPS):bacteria ratio was observed in DMADDM-treated biofilms. Persisters in biofilms significantly upregulated gtf gene expression, indicating an increase in the bacteria's ability to produce EPS and an elevated capability of cariogenic virulence. Carbon source metabolism was significantly reduced, as related metabolic genes were all downregulated in persisters. Concentrations of $0.1 \mathrm{mM}, 1 \mathrm{mM}$ and $10 \mathrm{mM}$ of extra glucose significantly reduced the number of persisters both in planktonic and biofilm conditions. The formation of noninheritable and multidrug tolerant persisters induced by DMADDM suggested that drug tolerance and new persistent eradication strategies should be considered for oral antibacterial agents.

International Journal of Oral Science Online publication 20 December 2017; e7; doi:10.1038/ijos.2017.46

Keywords: antibacterial quaternary ammoniums; dental caries; persistence; multidrug tolerance; Streptococcus mutans biofilms

\section{INTRODUCTION}

Dental caries, also known as "tooth decay", one of the most prevalent chronic diseases worldwide, are the main cause of oral pain and tooth loss. ${ }^{1}$ Dental caries not only affect oral health but also relate to some systematic diseases, such as diabetes, indicating that the prevention and treatment of dental caries are emergent. ${ }^{1}$ The dental plaque (oral biofilm) formed by oral bacteria on tooth surfaces plays an important role in the caries process. ${ }^{2}$ Streptococcus mutans was proved to be the major cariogenic facultative anaerobe in the oral cavity due to its ability to demineralize the tooth tissue through the increased consumption of fermentable carbohydrates and subsequent acid production. $^{3}$ S. mutans can also produce large quantities of extracellular polysaccharide to increase its adhesion through the exopolysaccharides (EPS) biosynthesis pathway, in which the $g t f$ genes encoding glucosyltransferase (GTF) play critical roles and are thought to be one of the primary virulence factors responsible for the development of dental caries. ${ }^{4}$ Therefore, S. mutans is an efficacious caries defensive target, and various antibacterial agents such as quaternary ammonium compounds (QAs) have been developed to combat cariogenic bacteria. ${ }^{5-6}$

QAs are cationic surfactants with a broad spectrum of antibacterial activities. $^{7-8}$ Their antibacterial mechanisms are not well known, but it is generally accepted that the predominant mode of action is "contact killing". The positively charged $\left(\mathrm{N}^{+}\right)$sites of QA molecules can attach

\footnotetext{
${ }^{1}$ State Key Laboratory of Oral Diseases \& National Clinical Research Center for Oral Diseases \& Department of Operative Dentistry and Endodontics, West China Hospital of Stomatology, Chengdu, China and ${ }^{2}$ Biomaterials \& Tissue Engineering Division, Department of Endodontics, Prosthodontics and Operative Dentistry, University of Maryland Dental School, Baltimore, USA

*These authors contributed equally to this work.

Correspondence: Professor L Cheng, State Key Laboratory of Oral Diseases \& National Clinical Research Center for Oral Diseases \& Department of Operative Dentistry and Endodontics, West China Hospital of Stomatology, No.14, 3rd Section, Renmin South Road, Chengdu 610041, China

E-mail: chengleidentist@163.com

or Professor B Ren, State Key Laboratory of Oral Diseases \& National Clinical Research Center for Oral Diseases \& Department of Operative Dentistry and Endodontics, West China Hospital of Stomatology, No.14, 3rd Section, Renmin South Road, Chengdu 610041, China

E-mail: renbiao@scu.edu.cn

Accepted 15 September 2017
} 
to the negatively charged bacterial cells. This interaction disrupts the electric balance of the cell membrane, which causes bacterial cells to burst under their own osmotic pressure. ${ }^{9-10}$ Meanwhile, the molecular weight and N-alkyl chain length are also reported to be associated with QA antibacterial activities. ${ }^{11-12}$ The quaternary ammonium dimethylaminododecyl methacrylate (DMADDM) (chemical formula: $\mathrm{C}_{19} \mathrm{H}_{38} \mathrm{NO}_{2}^{+}$), one of the 12-chain-length QAs, has been demonstrated as a new type of anti-caries QA with the ability to reduce the growth of cariogenic bacteria in different models in our lab. ${ }^{13-15}$ DMADDM had a remarkable antibacterial efficacy when added to a dental adhesive system and glass ionomer cement. ${ }^{15-16}$ Importantly, DMADDM could even reduce the proportion of $S$. mutans in multispecies biofilms and adjust a caries-related biofilm to develop toward a healthy one, revealing its potential value in anti-caries clinical applications.

For all antibacterial candidates, the development of resistance is a key evaluation item, as antibacterial resistance is becoming a serious risk for global health. ${ }^{17-18}$ The evolution of antibiotic resistance will lead to a predicted 10 million deaths annually by 2050 , even worse than cancer. ${ }^{19}$ The WHO also gave a report to examine antibiotic resistance globally in 2014 and held a high level global assembly to call for all countries and regions of the world to take actions to address this urgent problem. ${ }^{20}$ QAs were found to be invulnerable to developing antimicrobial resistance in S. mutans and Enterococcus faecalis in vitro. ${ }^{21}$ Recently, we found that quaternary ammonium monomers could induce drug resistance in Streptococcus gordonii. ${ }^{22}$ However, there is no report on the antimicrobial tolerance (persistence) of oral bacteria to QAs.

Persisters are a small fraction of individuals (usually $0.0001 \%-$ $0.1 \%$ ) in bacterial populations that transiently switch to a nongrowing state and thereby can survive high levels of antibiotics and stressful environments. ${ }^{23-24}$ Bacterial persisters were first described by Joseph W. Bigger in 1944 when penicillin was employed to sterilize cultures of pathogenic Staphylococcus aureus. ${ }^{25}$ Persisters, different from antibiotic resistant mutants, are genetically identical to but phenotypical variants of regular cells. When the persistent cells are recovered from the non-growth state, they are still sensitive to antibacterial agents, and they also exhibit the same small survival fraction when re-challenged with high concentrations of antibacterial agents. ${ }^{26-27}$ Persister cells are undetectable with routine clinical tests such as drug susceptibility tests. ${ }^{28}$ Persisters are thought to be responsible for many chronic clinical recalcitrant bacterial infections. ${ }^{29-30}$ Recent studies have reported that antibiotic tolerance even facilitates the evolution of resistance and that persisters may become a potential source of antibiotic-resistant bacteria. ${ }^{31-32}$ The mechanisms responsible for persister formation, survival and resuscitation are complicated and diverse. Nevertheless, the balance of toxinantitoxin (TA) molecules is thought to be an important regulation module. ${ }^{33-34}$ However, comprehensive understanding of persister cell formation is still needed.

Although many efforts and advances have been made to investigate the formation and eradication of persisters for various pathogens in recent years, few studies have reported the persistence of oral pathogens and related infectious diseases. ${ }^{29-35}$ A previous study found that Candida albicans strains isolated from the oral cavities of patients who received daily topical chlorhexidine (CHX) treatment exhibited increased level of persistence, suggesting the clinical correlation between $C$. albicans persistence and oral fungal infections, and indicating that cationic antibacterial agents (such as CHX) can induce oral microbial persistence. ${ }^{29}$ As a potential oral antibacterial candidate, the activities and safety of DMADDM have been evaluated in different models, but its risk to induce oral bacterial persistence has not been investigated. Here we investigated the persistent cell formation ability of the main cariogenic bacteria $S$. mutans challenged by DMADDM and determined the characteristics of these persisters for the first time. Certain carbon source metabolites, related eradication strategies and gene expression alterations were also examined to describe the possible persistence mechanisms.

\section{MATERIALS AND METHODS}

\section{Chemicals}

The antibacterial quaternary ammonium DMADDM was synthesized via a modified Menschutkin reaction as described in previous studies. ${ }^{13}$ Briefly, 2-bromoethyl methacrylate (BEMA) was the organo halide, and 1-(dimethylamino)dodecane (DMAD) was the tertiary amine. To a $50 \mathrm{~mL}$ vial with a magnetic stir bar were added $10 \mathrm{mmol}$ DMAD (Tokyo Chemical Industry, Tokyo, Japan), 10 mmol BEMA and $3 \mathrm{~g}$ of ethanol. The vial was capped and stirring performed at $70{ }^{\circ} \mathrm{C}$ for $24 \mathrm{~h}$. When the reaction was complete, the ethanol solvent was removed via evaporation, and the DMADDM yield was a clear, colorless and viscous liquid. Fourier transform infrared (FTIR) spectroscopy (Nicolet 6700, Thermo Scientific, Waltham, MA, USA) was used to verify the DMADDM as described in preliminary studies. ${ }^{13-14}$ Other chemicals, including tetracycline, chloramphenicol, ciprofloxacin, daptomycin, vancomycin, $\mathrm{NaF}$ and glucose, were purchased from Sigma-Aldrich, China. Ciprofloxacin, daptomycin and vancomycin were dissolved in DMSO (Merck-China), tetracycline and chloramphenicol in ethanol, and $\mathrm{NaF}$, glucose and DMADDM in double distilled water (DDW) to obtain the following stock concentrations: tetracycline $\left(1 \mathrm{mg} \cdot \mathrm{mL}^{-1}\right)$, chloramphenicol $\left(1 \mathrm{mg} \cdot \mathrm{mL}^{-1}\right)$, ciprofloxacin $\left(1 \mathrm{mg} \cdot \mathrm{mL}^{-1}\right)$, daptomycin $\left(1 \mathrm{mg} \cdot \mathrm{mL}^{-1}\right)$, vancomycin $\left(1 \mathrm{mg} \cdot \mathrm{mL}^{-1}\right), \mathrm{NaF}\left(50 \mathrm{mg} \cdot \mathrm{mL}^{-1}\right)$, glucose $\left(0.01,0.1,1 \mathrm{~mol} \cdot \mathrm{mL}^{-1}\right)$, and DMADDM $\left(1 \mathrm{mg} \cdot \mathrm{mL}^{-1}\right.$ and $\left.10 \mathrm{mg} \cdot \mathrm{mL}^{-1}\right)$. All the solutions were filtered for sterilization using a Millipore filter with a pore size of $0.22 \mu \mathrm{m}$ (Millipore Express, PES Membrane) and stored at $-20^{\circ} \mathrm{C}$ until use.

\section{S. mutans culture conditions and inoculation preparation}

The use of S. mutans bacteria (ATCC 700610, UA159, American Type Culture, Manassas, VA, USA) was approved by the State Key Laboratory of Oral Diseases, Sichuan University. S. mutans was routinely cultured in brain-heart infusion (BHI) broth (Difco, Sparks, $\mathrm{MD}$, USA) at $37^{\circ} \mathrm{C}$ anaerobically $\left(90 \% \mathrm{~N}_{2}, 5 \% \mathrm{CO}_{2}, 5 \% \mathrm{H}_{2}\right)$, and culture medium was supplemented with $1 \%$ sucrose (BHIS) to induce S. mutans biofilm growth. For inoculation preparation, $15 \mu \mathrm{L}$ of stock bacteria was added into $15 \mathrm{~mL}$ of BHI broth and incubated in the above condition for $16 \mathrm{~h}$. This $S$. mutans culture was then diluted by 10 -fold in the growth medium to form the inoculum.

\section{Persistence and heritability assay}

For the planktonic persistence assay, $1 \mathrm{~mL}$ of bacterial suspension $\left(1 \times 10^{6}\right.$ colony-forming units $(\mathrm{CFU})$ per $\left.\mathrm{mL}\right)$ was inoculated into a 24-well plate (Greiner, Germany), and $20 \mu \mathrm{L}$ of the stock $1 \mathrm{mg} \cdot \mathrm{mL}^{-1}$ DMADDM was added to reach a final concentration of $20 \mu \mathrm{g} \cdot \mathrm{mL}^{-1}$, followed by incubation for $48 \mathrm{~h}$ at $37^{\circ} \mathrm{C}$. For the biofilm persistence assay, biofilm growth was initiated by inoculating $1 \mathrm{~mL}$ of $S$. mutans BHIS suspension $\left(1 \times 10^{6} \mathrm{CFU}\right.$ per $\left.\mathrm{mL}\right)$ into each well of a 24 -well plate and incubating it for $24 \mathrm{~h}$ to develop a biofilm on the bottom of the plate. After incubation, planktonic cells were carefully removed from the biofilm by washing with phosphate-buffered saline (PBS) three times. Then, $1 \mathrm{~mL}$ of fresh BHIS medium was added followed by adding $20 \mu \mathrm{L}$ of the $10 \mathrm{mg} \cdot \mathrm{mL}^{-1}$ DMADDM stock to reach a final 
concentration of $200 \mu \mathrm{g} \cdot \mathrm{mL}^{-1}$. The plate underwent a $48 \mathrm{~h}$ incubation at $37^{\circ} \mathrm{C}$. Samples were picked at the indicated time points and were serially diluted. The viable cells were recovered on BHI agar plates. The CFU per $\mathrm{mL}$ were counted after $48 \mathrm{~h}$ of incubation.

Surviving colonies in the above assays were randomly picked, resuspended into fresh BHI broth and incubated at $37^{\circ} \mathrm{C}$ for $16 \mathrm{~h}$. This bacterial culture was then used to repeat the above procedures three times. The minimal inhibitory concentration (MIC) of the recovered S. mutans colonies to DMADDM was tested and compared with the original S. mutans strain. The MIC was determined by the conventional broth microdilution method using BHI as described previously. ${ }^{36}$ The MIC was defined as the lowest concentration of DMADDM that inhibited visible bacterial growth after $24 \mathrm{~h}$ of incubation.

\section{Multidrug tolerance assay}

S. mutans persisters were obtained both in planktonic and biofilm culture in 24-well plates according to the method described above, and then, $20 \mu \mathrm{L}$ of the stock tetracycline, chloramphenicol, ciprofloxacin, daptomycin, vancomycin and $\mathrm{NaF}$ solutions was added into the persistent culture system (planktonic and biofilm), separately, to reach a final concentration of $20 \mu \mathrm{g} \cdot \mathrm{mL}^{-1}$ (except that the final concentration of $\mathrm{NaF}$ was $1 \mathrm{mg} \cdot \mathrm{mL}^{-1}$ ). The plate was incubated for another $24 \mathrm{~h}$ at $37^{\circ} \mathrm{C}$. Then, samples were collected and plated on BHI agar plates after serial dilution, and the recovered CFUs were counted after $48 \mathrm{~h}$ of incubation.

\section{Live/dead bacteria and bacterial exopolysaccharides (EPS) staining assays}

For the confocal laser scanning microscopic imaging, biofilms were developed as described above except that they were grown on sterilized glass slides.

For live/dead staining, biofilms on the glass slides were stained using the BacLight live/dead bacterial viability kit (Molecular Probes, Eugene, OR, USA). ${ }^{37}$ Briefly, live bacteria were stained with SYTO9 to produce green fluorescence, whereas dead bacteria with compromised membranes were stained with propidium iodide (PI) to produce red fluorescence. Biofilm images were captured using a DMIRE2 confocal laser scanning microscope (Leica, Wetzlar, Germany) equipped with a $60 \times$ oil immersion objective lens.

EPS staining was conducted according to previous studies. ${ }^{16-38}$ The polysaccharides were stained by adding $2.5 \mu \mathrm{mol} \cdot \mathrm{mL}^{-1}$ Alexa Fluor 647-labeled dextran conjugate (Molecular Probes, Invitrogen Corp., Carlsbad, CA, USA) into the biofilm formation medium at the beginning of the experiment, and then, the culture was incubated at $37^{\circ} \mathrm{C}$. The bacteria of the biofilm were stained with $2.5 \mu \mathrm{mol} \cdot \mathrm{mL}^{-1}$ SYTO9 (Molecular Probes, Invitrogen Corp., Carlsbad, CA, USA) for $15 \mathrm{~min}$. The biofilms were imaged with a Leica DMIRE2 confocal laser scanning microscope equipped with a $60 \times$ oil immersion objective lens.

Each biofilm was scanned at five randomly selected positions. All three-dimensional reconstructions of the biofilms were rendered by Imaris 7.0 software (Bitplane, Zürich, Switzerland), and representative pictures are shown. The quantification of live/dead and EPS/bacteria volume ratios was performed with Image-Pro Plus (Media Cybernetics, Silver Spring, MD, USA) and COMSTAT, respectively.

\section{Quantitative real-time polymerase Chain reaction (PCR)}

Quantitative real-time PCR was used to quantify the expression of selected genes (gene names and descriptions are shown in Table 1),
Table 1 Name and description of genes used in this study

\begin{tabular}{ll}
$\begin{array}{ll}\text { Gene } \\
\text { name }\end{array}$ & Gene description \\
\hline gtfB & Glucosyltransferase-I \\
gtfC & Glucosyltransferase-SI \\
gtfD & Glucosyltransferase-S \\
adhE & Bifunctional acetaldehyde-CoA/alcohol dehydrogenase \\
ldh & L-lactate dehydrogenase \\
pdhC & Branched-chain alpha-keto acid dehydrogenase E2 subunit \\
pdhB & Pyruvate dehydrogenase E1 component subunit beta \\
$p d h A$ & Pyruvate dehydrogenase, TPP-dependent E1 component alpha-subunit \\
$p d h D$ & Dihydrolipoamide dehydrogenase
\end{tabular}

with $16 \mathrm{~S}$ rRNA as an internal control. Normal and persistent cells in S. mutans biofilms were collected by centrifugation $\left(4000 \mathrm{~g}, 4^{\circ} \mathrm{C}\right.$, $10 \mathrm{~min}$ ), and the samples were stored at $-20^{\circ} \mathrm{C}$ until RNA extraction. All gene-specific primer sequences are listed in Table 2. Total bacterial RNA isolation, reverse transcription of CDNA, and PCR amplification were carried out as previously described. ${ }^{39-40}$ Real-time PCR of triplicate samples was performed using the iCycler iQ detection system (Applied Biosystems, Foster City, CA), and the relative gene expression levels were determined based on the $2^{-\Delta \Delta C T}$ method.

\section{Carbon source metabolism assay}

To explore the effect of carbon source metabolism on the formation of S. mutans persisters, certain concentrations of glucoses were tested. Briefly, S. mutans persisters were obtained both in planktonic and biofilm culture according to the method described above, and then, $10 \mu \mathrm{L}$ of the stock $0.01,0.1$, and $1 \mathrm{~mol} \cdot \mathrm{mL}^{-1}$ glucose solutions was added to the persistent culture system to obtain a final concentration of $0.1,1$, and $10 \mathrm{mmol} \cdot \mathrm{mL}^{-1}$, respectively. A total of $10 \mu \mathrm{L}$ of DDW was added to a control group. The plate was incubated for another $24 \mathrm{~h}$ at $37^{\circ} \mathrm{C}$. Then, samples were collected and plated on BHI agar plates after serial dilution, and the recovered CFUs were counted after $48 \mathrm{~h}$ of incubation.

\section{Statistical analysis}

All experiments were performed in triplicate with at least three biological replicates. Student's $t$-test was performed to detect the significant effects of the variables. Statistical analysis was computed using SPSS software, version 16.0 (SPSS Inc., Chicago, IL, USA).

\section{RESULTS}

DMADDM induced $S$. mutans persistence both in planktonic and biofilm cultures

The MIC of S. mutans to DMADDM is $2 \mu \mathrm{g} \cdot \mathrm{mL}^{-1}$ (Table 3 ). When the planktonic and biofilm $S$. mutans cultures were challenged with 10 -fold $\left(20 \mu \mathrm{g} \cdot \mathrm{mL}^{-1}\right)$ and 100 -fold $\left(200 \mu \mathrm{g} \cdot \mathrm{mL}^{-1}\right) \mathrm{MIC}$, respectively, typical biphasic killing curves were observed, including a stage with the rapid killing of sensitive cells and a stage with the survival of a small fraction of persistent cells (Figure $1 \mathrm{a}$ and $1 \mathrm{~b}$ ). In particular, DMADDM treatment of $S$. mutans planktonic and biofilm cultures resulted in the decrease of survival bacteria by two (planktonic) and four (biofilm) orders of magnitude within the first $12 \mathrm{~h}$ and $24 \mathrm{~h}$, respectively. A plateau phase followed, confirming the presence of high-level DMADDM-tolerant persisters both in S. mutans planktonic and biofilm cultures (Figure $1 \mathrm{a}$ and $1 \mathrm{~b}$ ). After re-incubation of the persistent isolates, they could regrow to a population that was still as sensitive to DMADDM as the original population 
$\left(\mathrm{MIC}=2 \mu \mathrm{g} \cdot \mathrm{mL}^{-1}\right)$ (Supplementary Table 1$)$ and exhibited the same biphasic killing pattern (Figure 1c and 1d) when challenged with a high concentration of DMADDM, indicating that these persisters were non-heritable.

Next, we observed the distribution of persistent cells in biofilms. Representative live/dead bacterial staining images from both $200 \mu \mathrm{g} \cdot \mathrm{mL}^{-1}$ DMADDM- and DDW (control)-treated biofilms are shown in Figure 2a. The control group had almost full coverage of live

Table 2 Real-time PCR primers used in this study

\begin{tabular}{|c|c|}
\hline Primers & Nucleotide Sequence $\left(5^{\prime}-3^{\prime}\right)$ \\
\hline \multirow[t]{2}{*}{$16 S$ rRNA } & FW-AGCGTTGTCCGGATTTATTG \\
\hline & RV-CTACGCATTTCACCGCTACA \\
\hline \multirow[t]{2}{*}{ gtfB } & FW-CACTATCGGCGGTTACGAAT \\
\hline & RV-CAATTTGGAGCAAGTCAGCA \\
\hline \multirow[t]{2}{*}{ gtfC } & FW-GATGCTGCAAACTTCGAACA \\
\hline & RV-TATTGACGCTGCGTTTCTTG \\
\hline \multirow[t]{2}{*}{$g t f D$} & FW-TTGACGGTGTTCGTGTTGAT \\
\hline & RV-AAAGCGATAGGCGCAGTTTA \\
\hline \multirow[t]{2}{*}{ adhE } & FW-ATTAACCACTCACTCGCCCA \\
\hline & RV-CGCGAGCAATATCCGCATAA \\
\hline \multirow[t]{2}{*}{ Idh } & FW-CTTCCTCGTTGCTGCTAACC \\
\hline & RV-TGGCATGAGACCATACTGCA \\
\hline \multirow[t]{2}{*}{$p d h A$} & FW-GTATGCAGGTGAAGAAGCCG \\
\hline & RV-AAAACCGCCACCAACCATAC \\
\hline \multirow[t]{2}{*}{$p d h B$} & FW-AGCAAAACGAAGAAGCCTGG \\
\hline & RV-CATTTTCGACCCTTGGCCAA \\
\hline \multirow[t]{2}{*}{$p d h C$} & FW-TTGGTCAAGAAGGTGAGGCT \\
\hline & RV-CCGTCCGTCTTCATGCTTTT \\
\hline \multirow[t]{2}{*}{$p d h D$} & FW-TGGCTTCCTTTGGACTGAGT \\
\hline & RV-TTCGCCAACAATAACAGCCC \\
\hline
\end{tabular}

FW, forward; RV, reverse.
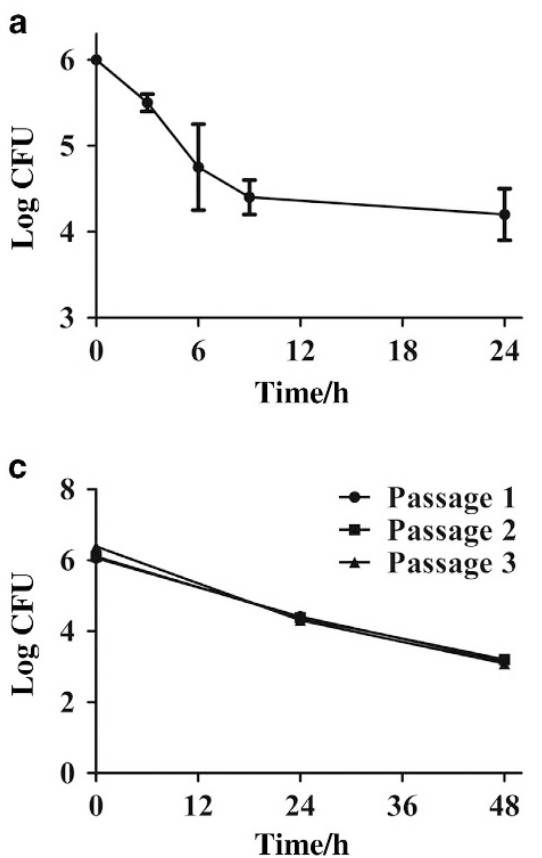

bacteria, while only a few live persisters survived after being treated with $200 \mu \mathrm{g} \cdot \mathrm{mL}^{-1}$ DMADDM. The thickness of the biofilm and the live/dead ratio were remarkably decreased after the DMADDM treatment (Figure $2 \mathrm{~b}$ and $2 \mathrm{c}$ ), indicating the strong antibacterial activity of DMADDM and the tolerant ability of persisters to lethal concentrations of DMADDM. The distributions of live and dead bacteria were similar except that dead cells were more common in DMADDM-treated biofilms (Figure 2c).

\section{S. mutans persisters were multidrug tolerant}

Six different types of antibiotics exhibiting various antibacterial mechanisms at high concentrations (over the MICs, Table 3) were employed. As shown in Figure 3, after the formation of persisters at $24 \mathrm{~h}$, the six types of antibiotics were added and treated for another $24 \mathrm{~h}$; however, none of the antibiotics were able to completely eliminate S. mutans persisters both in planktonic (Figure 3a) and biofilm (Figure $3 \mathrm{~b}$ ) conditions. Daptomycin and vancomycin slightly reduced the persister numbers in planktonic cultures (Figure 3a), but there were no effects on the persisters in biofilms (Figure 3b),

Table 3 MIC values of $S$. mutans for different antibacterial drugs used in this study

\begin{tabular}{lc}
\hline Antibacterial drug & MIC value $/\left(\mu \mathrm{g} \cdot \mathrm{mL}^{-1}\right)$ \\
\hline DMADDM & 2 \\
Tetracycline & 0.625 \\
Chloramphenicol & 2.44 \\
Ciprofloxacin & 5 \\
Daptomycin & 20 \\
Vancomycin & 1.25 \\
NaF & 250 \\
\hline
\end{tabular}

DMADDM, dimethylaminododecyl methacrylate.

b

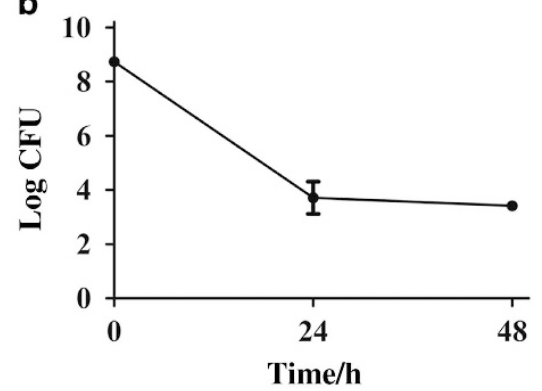

d

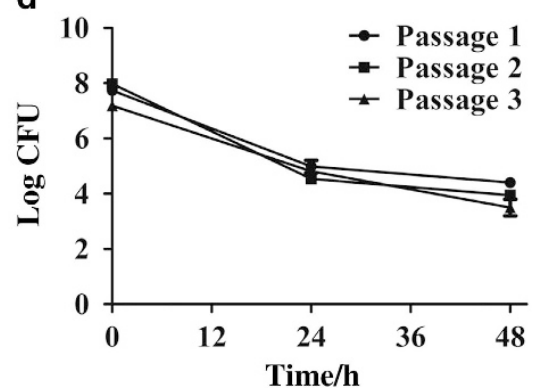

Figure 1 Formation of non-heritable DMADDM-tolerant S. mutans persisters. (a) Time-dependent killing curves of S. mutans planktonic cultures. (b) Timedependent killing curves of $S$. mutans biofilm cultures. (c) Non-heritable nature of $S$. mutans planktonic persisters. (d) Non-heritable nature of $S$. mutans biofilm persisters. The data are presented as the mean \pm standard deviation $(n=6)$. DMADDM, dimethylaminododecyl methacrylate; CFU, colony-forming units. 
a

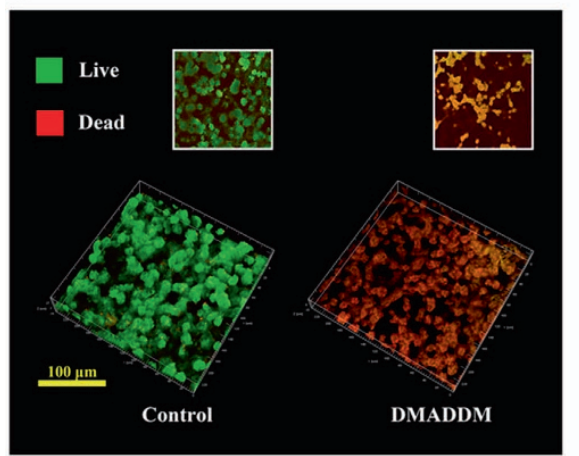

b

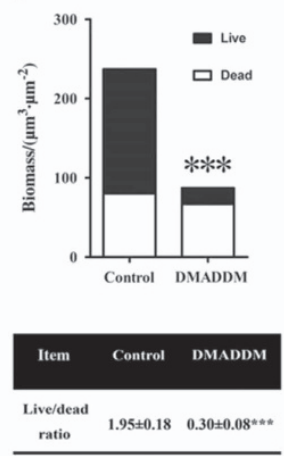

C

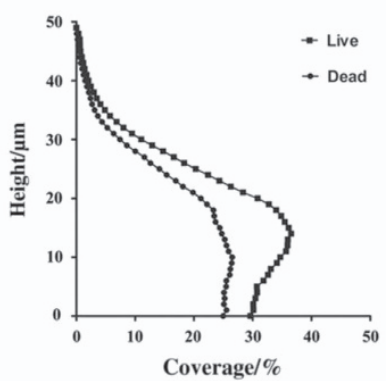

DMADDM

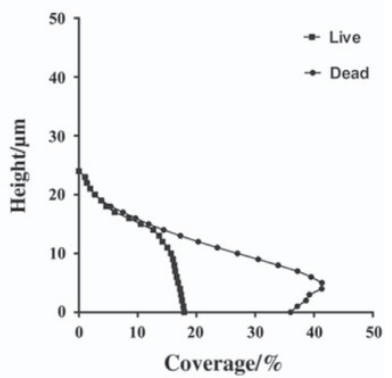

Figure 2 Live/dead bacteria staining of $\boldsymbol{S}$. mutans normal and persister biofilms. (a) Live/dead bacteria staining images of $S$. mutans normal and persister biofilms. (b) Quantitative analysis of live/dead biomass and ratio. Results are averaged from five randomly selected positions of each sample, $* * * P<0.001$. (c) Live and dead bacteria distributions of each layer in normal and persister biofilms. DMADDM, dimethylaminododecyl methacrylate.
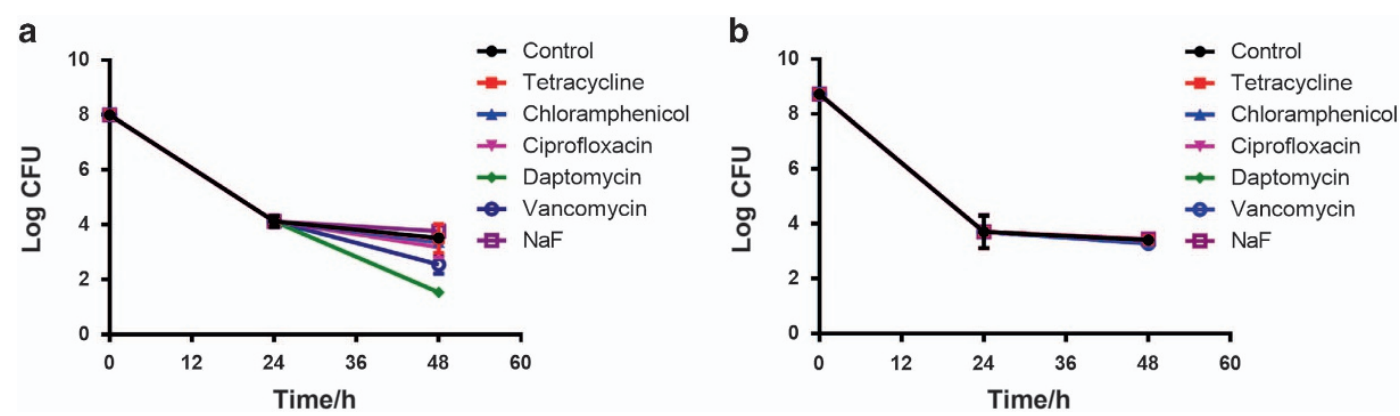

Figure 3 Multidrug tolerance of $S$. mutans persisters. (a) Multidrug tolerance of $S$. mutans planktonic persisters. (b) Multidrug tolerance of $S$. mutans biofilm persisters. The data are presented as the mean \pm standard deviation $(n=6)$. CFU, colony-forming units.

a

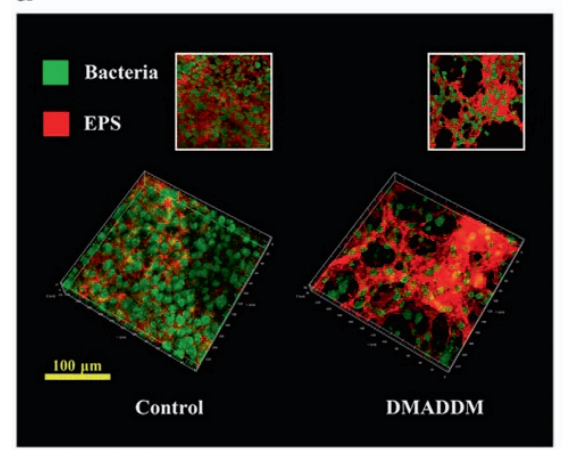

b

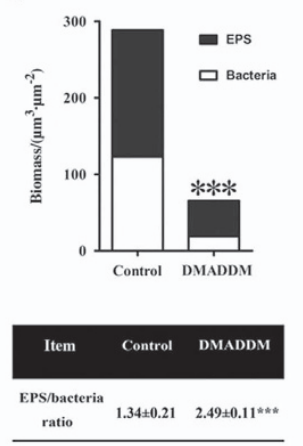

C

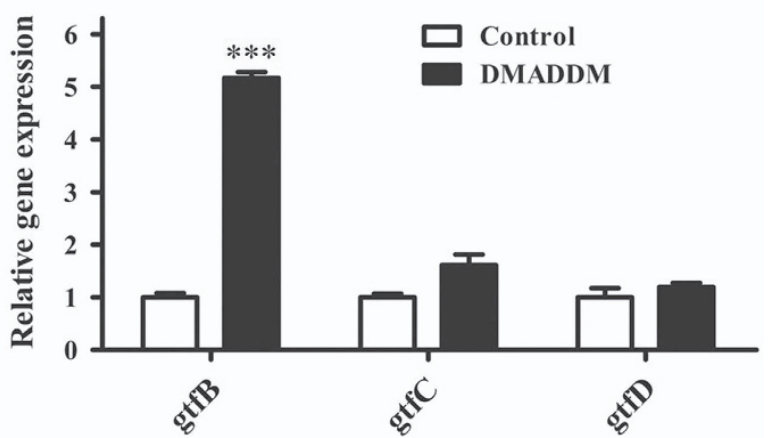

Figure 4 EPS staining of $S$. mutans normal and persister biofilms. (a) EPS staining images of S. mutans normal and persister biofilms; (b) Quantitative analysis of EPS/bacteria biomass and ratio. Results are averaged from five randomly selected positions of each sample, ${ }^{* * *} P<0.001$. (c) Relative gene expression of EPS production-related genes. The data are presented as the mean \pm standard deviation $(n=6),{ }^{* * *} P<0.001$. DMADDM, dimethylaminododecyl methacrylate.

suggesting the better multidrug tolerant abilities of $S$. mutans persisters induced by DMADDM in biofilms.

\section{S. mutans persisters enhanced EPS production ability}

Next, we evaluated the cariogenic virulence change of persistent cells. Typical images of bacteria/EPS staining of $S$. mutans normal and persister biofilms are shown in Figure 4a. Quantitative analysis showed that although the total EPS production was significantly reduced in DMADDM-challenged biofilms, these biofilms had higher EPS:bacteria ratios than that in the normal control biofilms (Figure $4 \mathrm{~b}$, $P<0.001$ ), indicating that a large amount of relict EPS matrix surrounded $S$. mutans persisters to protect them from different antibiotic challenges and stresses, making them more difficult to eradicate (Figure $3 \mathrm{~b}$ ). We then measured the expression levels of $g t f$ genes, which are responsible for EPS production, from the normal cells and persistent cells in the biofilm. The gene $g t f B$, a key gene in EPS production, was significantly upregulated (Figure 4c), suggesting the increased cariogenic virulence of $S$. mutans persisters.

S. mutans persister formation was associated with carbon source metabolism

Persisters are generally considered to be dormant cells. We measured the carbon source metabolism of persistent cells by monitoring the expression of several key glycolysis- and citrate cycle-related genes, 


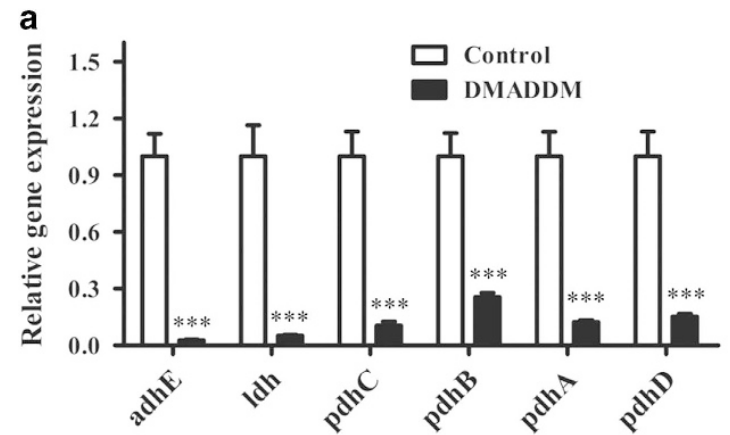

b

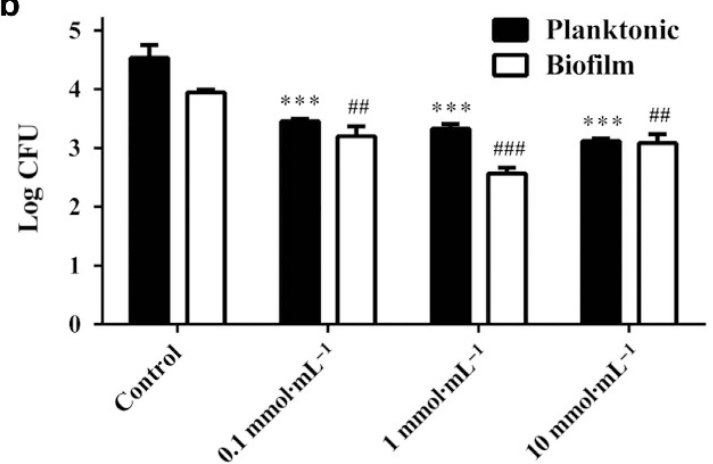

Figure 5 Effect of carbon source metabolism on $S$. mutans persister formation. (a) Relative gene expression of carbon source metabolism-related genes treated with DDW (control) or $200 \mu \mathrm{g} \cdot \mathrm{mL}^{-1}$ DMADDM. The data are presented as the mean \pm s.d. $(n=6)$, ${ }^{* *} P<0.001$. (b) Effect of different concentrations of glucose on $S$. mutans planktonic and biofilm persisters; $\# \# P<0.01,{ }^{* *} P<0.001$, or \#\#\#P<0.001. The data are presented as the mean \pm s.d. $(n=6)$. DMADDM, dimethylaminododecyl methacrylate.

including adhE, $l d h$, and $p d h A / B / C / D$. Predictably, the expression levels of these genes were all significantly downregulated in persistent cells compared to the control group (Figure 5a), suggesting the low metabolic level of $S$. mutans persisters and leading to the hypothesis that the activation of carbon source metabolism may be a possible strategy for the eradication of $S$. mutans persisters. As expected, with the addition of extra glucose to the culture, the presence of persisters both in planktonic and biofilm conditions was significantly reduced under the concentrations of $0.1,1$ and $10 \mathrm{mmol} \cdot \mathrm{mL}^{-1}$ (Figure 5b).

\section{DISCUSSION}

The generation of bacterial persister cells is a critical problem in the application of antibacterial agents since bacterial persisters are usually involved in the relapses of chronic infections ${ }^{41}$ and in the induction of bacterial resistance. ${ }^{31-42}$ The present study investigated the ability of the cariogenic bacterial species $S$. mutans to form persisters induced by DMADDM, an antibacterial QA, in vitro and determined the characteristics of these persisters for the first time. The result demonstrated that $S$. mutans was capable of persistence formation and surviving the QA anti-caries treatment, indicating that new drug tolerance evaluation should be performed when developing new antibacterial agents for use in oral diseases. When the antibacterial agent is removed, such as through the drop of antibacterial filling materials for caries or via microleakage between restoration materials and tooth tissues, persisters can regrow to a new population, which may be associated with the recurrence and refractory nature of secondary dental caries. ${ }^{24,28-43}$ The non-heritable and phenotypical variation has also been demonstrated and well-studied in other bacterial persisters such as Escherichia coli and S. aureus. ${ }^{44-45}$ However, previous studies mainly focused on the induction of persistence by bacteriostatic antibiotics such as penicillin. ${ }^{44-45}$ Different from these antibiotics, which usually work through specific targets in the biological process of bacteria, bactericidal quaternary ammoniums are commonly thought to be "contact killing" and therefore less likely to lead to the development of antimicrobial resistance. ${ }^{21-22}$ However, the present study proved for the first time that DMADDM, a quaternary ammonium, could induce persistence in S. mutans. The presence of $S$. mutans persister cells could be detected by the "biphasic killing" phenomenon of bacterial cultures exposed to lethal concentrations of DMADDM.

The specific mechanisms of persister formation still require comprehensive investigation. Currently, the survival of persisters can roughly be explained by their transition into a "dormant" state, as antibiotics' killing effects on bacteria often depend on their active growth. ${ }^{46-47}$ We found that the dormant $S$. mutans persisters can even tolerant high levels of six clinical antibiotics with different antibacterial mechanisms, including those that target protein biosynthesis, DNA biosynthesis and replication, the cell membrane, the cell wall and cell metabolic pathways. More importantly, S. mutans persisters can tolerant $1 \mathrm{mg} \cdot \mathrm{mL}^{-1}$ fluoride, which is considered to be the most successful agent for dental caries prevention, indicating the high risks of S. mutans persistence in dental caries. Previous studies have also reported that dormant persisters enhance efflux pump activity to ensure their survival under antibacterial attack. ${ }^{48-49}$ In our study, persisters in biofilms had better multidrug tolerance compared to planktonic persisters because the daptomycin and vancomycin treatments slightly reduced the planktonic persisters, making them more virulent and difficult to remove. The persister cell reduction by daptomycin and vancomycin in planktonic culture may result from the cross targets between DMADDM and these two antibiotics. ${ }^{50-51}$

The extracellular matrix of dental plaque is an important virulence factor for the development of dental caries and periodontal disease. $^{52-54}$ Matrix constituents, such as EPS, the biopolymers in which biofilm microorganisms are embedded, play an important role in bacterial adhesion. ${ }^{55-56}$ The higher EPS:bacteria ratio in the DMADDM-challenged biofilm indicated that the $S$. mutans persisters induced in the biofilm were protected by more relict EPS matrix to fight against extra stresses such as lethal levels of different antibiotics. The DMADDM-induced persister in the biofilm enhanced the EPS production ability by means of the upregulation of $g t f B$ expression, suggesting that $S$. mutans persisters can produce more EPS to enhance their cariogenic virulence and promote the adhesion of other pathogens, such as C. albicans, to form multispecies biofilms when the antibacterial treatments are reduced or removed. ${ }^{57}$

Previous work found that specific metabolites facilitate the killing of bacterial persisters by aminoglycosides, ${ }^{58}$ highlighting the importance of the metabolic environment to persisters. Here we demonstrated that the expression levels of several carbon source metabolism-related genes were all downregulated in DMADDM-induced S. mutans persisters, which was consistent with their reduction of growth rate and metabolism. We confirmed the growth activation of persisters by demonstrating that the addition of an extra carbon source can reduce the level of $S$. mutans persistence, indicating that glucose might change the "dormant" persisters into "active" ones, which were sensitive to the antibacterial agent DMADDM. However, the precise mechanisms need to be further investigated since it has also been reported that carbon source transitions stimulated the formation of fluoroquinolone persisters in E. coli. ${ }^{59}$ Since the mechanisms of persistent cell formation are dynamic, ${ }^{60}$ the eradication strategies must be 
investigated precisely based on different bacteria and persistent formation conditions.

\section{CONCLUSION}

The present study identified the non-heritable and multidrug tolerant S. mutans persisters induced by the antibacterial quaternary ammonium DMADDM both in planktonic and biofilm cultures for the first time. In accordance with their decreased metabolism and dormant state, carbon source metabolism-related genes were downregulated in DMADDM-tolerant $S$. mutans persisters, and certain concentrations of glucose significantly reduced the $S$. mutans persistent level. Meanwhile, S. mutans persisters enhanced their cariogenic virulence by means of the increase of their EPS production ability through the upregulation of $g t f$ genes. The persisters were tolerant to high concentrations of different antibiotics with various antibacterial mechanisms, including fluoride. The combination of DMADDM and high levels of other antibiotics at the persistent stage was ineffective, indicating that a new eradication method, such as the addition of extra glucose in our study, is needed to combat persisters in the oral cavity instead of simply using different antibiotics or increasing their clinical dosages. The detailed mechanisms of the overall metabolic shift and the S. mutans persister formation, survival and resuscitation should be further investigated to combat $S$. mutans persisters in oral infectious diseases, and new evaluation items based on the resistance and tolerance of oral antibacterial materials/agents should be constructed.

\section{ACKNOWLEDGEMENTS}

This study was supported by the National Key Research and Development Program of China 2016YFC1102700 (X.Z.); the National Natural Science Foundation of China grants 81372889 (LC), 81600858 (BR) and 81430011 (XZ); the Recruitment Program for Young Professionals (MF); and the Youth Grant of the Science and Technology Department of Sichuan Province, China 2017JQ0028 (L.C.).

1 Selwitz RH, Ismail AI, Pitts NB. Dental caries. Lancet 2007; 369(9555): 51-59.

2 Kuramitsu HK, He X, Lux R et al. Interspecies interactions within oral microbial communities. Microbiol Mol Biol Rev 2008; 71(4): 653-670.

$3 \mathrm{Xu} \mathrm{J}, \mathrm{Li} \mathrm{Y}, \mathrm{Cao} \mathrm{X}$ et al. The effect of eugenol on the cariogenic properties of Streptococcus mutans and dental caries development in rats. Exp Ther Med 2013; 5 (6): 1667-1670.

4 Yamashita Y, Bowen WH, Burne RA et al. Role of the Streptococcus mutans gtf genes in caries induction in the specific-pathogen-free rat model. Infect Immun 1993; 61(9): 3811-3817.

5 Ge Y, Wang S, Zhou X et al. The use of quaternary ammonium to combat dental caries. Materials(Basel) 2015; 8(6): 3532-3549.

6 Eckert R, Sullivan R, Shi W. Targeted antimicrobial treatment to re-establish a healthy microbial flora for long-term protection. Adv Dent Res 2012; 24(2): 94-97.

7 Zaltsman N, Keslershvero D, Weiss El et al. Synthesis variants of quaternary ammonium polyethyleneimine nanoparticles and their antibacterial efficacy in dental materials. $J$ Appl Biomater Funct Mater 2016; 14(2): e205-e211.

8 Zubris DL, Minbiole KP, Wuest WM. Polymeric quaternary ammonium compounds: versatile antimicrobial materials. Curr Top Med Chem 2017; 17(3): 305-318.

9 Beyth N, Yudovinfarber I, Bahir R et al. Antibacterial activity of dental composites containing quaternary ammonium polyethylenimine nanoparticles against Streptococcus mutans. Biomaterials 2006; 27(21): 3995-4002.

10 Mei L, Ren Y, Loontjens TJ et al. Contact-killing of adhering streptococci by a quaternary ammonium compound incorporated in an acrylic resin. Int $J$ Artif Organs 2012; 35(10): 854-863.

$11 \mathrm{He} \mathrm{J}$, Söderling E, Vallittu PK et al. Investigation of double bond conversion, mechanical properties, and antibacterial activity of dental resins with different alkyl chain length quaternary ammonium methacrylate monomers (QAM). J Biomater Sci Polym Ed 2013; 24(5): 565-573.

$12 \mathrm{Li} \mathrm{F}$, Weir MD, Xu HH. Effects of quaternary ammonium chain length on antibacterial bonding agents. J Dent Res 2013; 92(10): 932-938.

13 Cheng L, Weir MD, Zhang $\mathrm{K}$ et al. Dental primer and adhesive containing a new antibacterial quaternary ammonium monomer dimethylaminododecyl methacrylate. J Dent 2013; 41(4): 345-355.
14 Wang S, Zhang K, Zhou X et al. Antibacterial effect of dental adhesive containing dimethylaminododecyl methacrylate on the development of Streptococcus mutans biofilm. Int J Mol Sci 2014; 15(7): 12791-12806.

15 Zhang K, Wang S, Zhou X et al. Effect of antibacterial dental adhesive on multispecies biofilms formation. J Dent Res 2015; 94(4): 622-629.

16 Wang $\mathrm{S}, \mathrm{Ge} \mathrm{Y}$, Zhou $\mathrm{X}$ et al. Effect of anti-biofilm glass-ionomer cement on Streptococcus mutans biofilms. Int J Oral Sci 2016; 8(2): 76-83.

17 Hede K. Antibiotic resistance: An infectious arms race. Nature 2014; 509(7498): S2-S3.

18 Yoneyama H, Katsumata R. Antibiotic resistance in bacteria and its future for novel antibiotic development. Biosci Biotechnol Biochem 2006; 70(5): 1060-1075.

19 O'Brien TF, Stelling J. Integrated multilevel surveillance of the world's infecting microbes and their resistance to antimicrobial agents. Clin Microbiol Rev 2011; 24(2): 281-295.

20 Dominey-Howes D, Bajorek B, Michael CA et al. Applying the emergency risk management process to tackle the crisis of antibiotic resistance. Front Microbiol 2015; 6: 927.

21 Kitagawa $\mathrm{H}$, Izutani N, Kitagawa $\mathrm{R}$ et al. Evolution of resistance to cationic biocides in Streptococcus mutans and Enterococcus faecalis. J Dent 2016; 47: 18-22.

22 Wang S, Wang $\mathrm{H}$, Ren B et al. Do quaternary ammonium monomers induce drug resistance in cariogenic, endodontic and periodontal bacterial species? Dent Mater 2017; 33: 1127-1138.

23 Gefen O, Balaban NQ. The importance of being persistent: heterogeneity of bacterial populations under antibiotic stress. FEMS Microbiol Rev 2009; 33(4). 704-717.

24 Lewis K. Persister cells. Annu Rev. Microbiol 2010; 64(64): 357-372.

25 Bigger JW. The bactericidal action of penicillin on Staphylococcus pyogenes. Ir J Med Sci 1944; 19(12): 585-595.

26 Jayaraman R. Bacterial persistence: some new insights into an old phenomenon. J Biosci 2008; 33(5): 795-805.

27 Levin BR, Rozen DE. Non-inherited antibiotic resistance. Nat Rev Microbiol 2006; 4(7): 556-562.

28 Fauvart M, De Groote VN, Michiels J. Role of persister cells in chronic infections: clinical relevance and perspectives on anti-persister therapies. J Med Microbio/ 2011; 60(6): 699-709.

29 Lafleur MD, Qi Q, Lewis K. Patients with long-term oral carriage harbor high-persister mutants of Candida albicans. Antimicrob Agents Chemother 2010; 54(1): 39-44.

30 Mulcahy LR, Burns JL, Lory S et al. Emergence of Pseudomonas aeruginosa strains producing high levels of persister cells in patients with cystic fibrosis. J Bacteriol 2010; 192(23): 6191-6199.

31 Levin-reisman I, Ronin I, Gefen 0 et al. Antibiotic tolerance facilitates the evolution of resistance. Science 2017; 355(6327): 826-830.

32 Lewis K, Shan Y. Why tolerance invites resistance. Science 2017; 355(6327): 796.

33 Page R, Peti W. Toxin-antitoxin systems in bacterial growth arrest and persistence. Nat Chem Biol 2016; 12(4): 208-214.

34 Wen Y, Behiels E, Devreese B. Toxin-Antitoxin systems: their role in persistence, biofilm formation, and pathogenicity. Pathog Dis 2014; 70(3): 240-249.

35 Leung V, Ajdic D, Koyanagi S et al. The formation of Streptococcus mutans persisters induced by the quorum-sensing peptide pheromone is affected by the LexA regulator. $J$ Bacteriol 2015; 197(6): 1083-1094.

36 Haraszthy VI, Reynolds HS, Sreenivasan PK et al. Media- and method-dependent variations in minimal inhibitory concentrations of antiplaque agents on oral bacteria. Lett App/ Microbiol 2006; 43(3): 256-261.

37 Zheng $X$, Zhang $\mathrm{K}$, Zhou $X$ et al. Involvement of gshAB in the interspecies competition within oral biofilm. J Dent Res 2013; 92(9): 819-824.

38 Klein MI, Duarte S, Xiao J et al. Structural and molecular basis of the role of starch and sucrose in Streptococcus mutans biofilm development. App/ Environ Microbiol 2009; 75(3): 837-841.

$39 \mathrm{Li} \mathrm{M}$, Huang $\mathrm{R}$, Zhou $\mathrm{X}$ et al. Effect of nicotine on dual-species biofilms of Streptococcus mutans and Streptococcus sanguinis. FEMS Microbiol Lett 2014; 350(2): 125-132.

40 Zhang $\mathrm{K}$, Ren $\mathrm{B}$, Zhou $\mathrm{X}$ et al. Effect of antimicrobial denture base resin on multispecies biofilm formation. Int J Mol Sci 2016; 17(7): 1033.

41 Orman MA, Brynildsen MP. Establishment of a method to rapidly assay bacterial persister metabolism. Antimicrob Agents Chemother 2013; 57(9): 4398-4409.

42 Cohen NR, Lobritz MA, Collins JJ. Microbial persistence and the road to drug resistance. Cell Host Microbe 2013; 13(6): 632-642.

43 Conlon BP. Staphylococcus aureus chronic and relapsing infections: evidence of a role for persister cells: an investigation of persister cells, their formation and their role in $S$. aureus disease. Bioessays 2014; 36(10): 991-996.

44 Keren I, Kaldalu N, Spoering A et al. Persister cells and tolerance to antimicrobials. Fems Microbiol Lett 2004; 230(1): 13-18.

45 Lechner S, Lewis K, Bertram R. Staphylococcus aureus persisters tolerant to bactericidal antibiotics. J Mol Microbiol Biotechnol 2012; 22(4): 235-244.

46 Kohanski MA, Dwyer DJ, Collins JJ. How antibiotics kill bacteria: from targets to networks. Nat Rev Microbiol 2010; 8(6): 423-435.

47 Lambert PA. Bacterial resistance to antibiotics: modified target sites. Adv Drug Deliv Rev 2005; 57(57): 1471-1485.

$48 \mathrm{Pu}$ Y, Ke Y, Bai F. Active efflux in dormant bacterial cells-new insights into antibiotic persistence. Drug Resist Updat 2017; 30: 7-14.

$49 \mathrm{Pu}$ Y, Zhao Z, Li Y et al. Enhanced efflux activity facilitates drug tolerance in dormant bacterial cells. Mol Cell 2016; 62(2): 284-294. 
50 Butler MS, Hansford KA, Blaskovich MA et al. Glycopeptide antibiotics: back to the future. J Antibiot 2014; 67(9): 631-644.

51 Pertel PE, Eisenstein BI, Link AS et al. The efficacy and safety of daptomycin vs. vancomycin for the treatment of cellulitis and erysipelas. Int J Clin Pract 2009; 63(3): 368-375.

52 Beikler T, Flemmig TF. Oral biofilm-associated diseases: trends and implications for quality of life, systemic health and expenditures. Periodontol 2011; 55(1): 87-103.

53 Gün I, EkiNci FY. Biofilms: microbial life on surfaces. Emerg Infect Dis 2009; 8(9): $881-890$

54 Mihai MM, Holban AM, Giurcaneanu C et al. Microbial biofilms: impact on the pathogenesis of periodontitis, cystic fibrosis, chronic wounds and medical devicerelated infections. Curr Top Med Chem 2015; 15(16): 1552-1576.

55 Flemming HC, Neu TR, Wozniak DJ. The EPS matrix: the "house of biofilm cells". J Bacteriol 2007; 189(22): 7945-7947.

56 Xiao J, Klein MI, Falsetta ML et al. The exopolysaccharide matrix modulates the interaction between 3D architecture and virulence of a mixed-species oral biofilm. PLoS Pathog 2012; 8(4): e1002623.

57 Falsetta ML, Koo H. Beyond mucosal infection: a role for C. albicans-Streptococcal interactions in the pathogenesis of dental caries. Curr Oral Health Rep 2014; 1(1): 86-93.
58 Allison KR, Brynildsen MP, Collins JJ. Metabolite-enabled eradication of bacterial persisters by aminoglycosides. Nature 2011; 473(7346): 216-220.

59 Amato SM, Orman MA, Brynildsen MP. Metabolic control of persister formation in Escherichia coli. Mol Cell 2013; 50(4): 475-487.

60 Allison KR, Brynildsen MP, Collins JJ. Heterogeneous bacterial persisters and engineering approaches to eliminate them. Curr Opin Microbiol 2011; 14(5): 593-598.

(c) (1) $\odot$ This work is licensed under a Creative Commons Attributioncc) NonCommercial-NoDerivs 4.0 International License. The images or other third party material in this article are included in the article's Creative Commons license, unless indicated otherwise in the credit line; if the material is not included under the Creative Commons license, users will need to obtain permission from the license holder to reproduce the material. To view a copy of this license, visit http://

creativecommons.org/licenses/by-nc-nd/4.0/

(C) The Author(s) 2017

Supplementary Information for this article can be found on the International Journal of Oral Science website (http://www.nature.com/ijos) 